\title{
Analisis Sistem Pendukung Keputusan Penentuan Kasi Terbaik Menerapkan Metode OCRA dengan Pembobotan Rank Order Centroid (ROC)
}

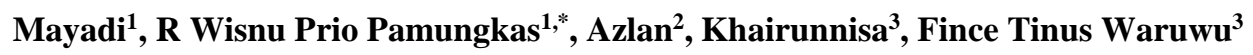 \\ ${ }^{1}$ Informatika, Fakultas Ilmu Komputer, Universitas Bhayangkara Jakarta Raya, Jakarta, Indonesia \\ ${ }^{2}$ Prodi Sistem Informasi, STMIK Triguna Dharma, Medan, Indonesia \\ ${ }^{3}$ Program Studi Teknik Informatika, STMIK Budi Darma, Medan, Indonesia \\ Email: ${ }^{1}$ mayadi@dsn.ubharajaya.ac.id, ${ }^{2,{ }^{*}}$ wisnu.prio@dsn.ubharajaya.ac.id, ${ }^{3}$ azlansaja19@gmail.com, ${ }^{4}$ nisak030720@gmail.com, \\ ${ }^{5}$ fincedav@gmail.com \\ Email Penulis Korespondensi: wisnu.prio@dsn.ubharajaya.ac.id \\ Submitted: 20/12/2021; Accepted: 28/12/2021; Published: 31/12/2021
}

\begin{abstract}
Abstrak-Kasi (Kepala Seksi) pada suatu pemerintahan desa merupakan unsur pelaksana operasional pemerintahan yang dipimpin seorang kepala seksi. Peran kasi sangatlah dibutuhkan dalam meningkatkan kualitas pemerintahan desa. Dalam penentuan Kasi terbaik haruslah memenuhi beberapa kriteria seperti Lama Bekerja, Pengabdian Masyarakat, Loyalitas Kerja, Usia dan Pendidikan Terakhir. Maka dari itu dibutuhkan suatu Sistem Pendukung Keputusan (SPK) untuk mengatasi masalah tersebut menggunakan metode Operational Competitiveness Rating Analysis (OCRA) untuk memperoleh data-data yang dibutuhkan dalam menentukan kriteria Kasi terbaik. Sehingga dalam penelitian penentuan Kasi terbaik ini, menghasilkan alternatif A5 dengan nilai 1.347 sebagai alternatif terbaik.
\end{abstract}

Kata Kunci: Sistem Pendukung Keputusan; Kasi; Metode OCRA

Abstract-Kasi (Section Head) in a village government is an element of implementing government operations led by a section head. The role of the cation is very much needed in improving the quality of village governance. In determining the best Kasi must meet several criteria such as Length of Work, Community Service, Work Royality, Age and Last Education. Therefore, a Decision Support System (DSS) is needed to overcome this problem using Operational Competitiveness Rating Analysis (OCRA) to obtain the data needed to determine the best Kasi criteria. So that in this research to determine the best Kasi, it produces alternative A5 with a value of 1,347 as the best alternative.

Keywords: Decision Support System; Kasi; OCRA Method

\section{PENDAHULUAN}

Kasi adalah kepala seksi bagian dari pemerintahan desa atau perangkat desa yang berkedudukan dalam unsur pelaksanaan teknis yang mengemban tugas dalam membantu Kepala Desa yang bertugas sebagai operasional di bidang pemerintahan desa. Kepala seksi (Kasi) terdapat 3 (tiga) bagian diantaranya seksi kesejahteraan, seksi palayanan dan seksi pemerintahan. Yang dimana masing-masing seksi dipimpin oleh seorang Kepala Seksi (Kasi)[1].

Kasi yang bertugas dalam membantu kepala desa sebagai pelaksana tugas operasional, dalam melaksanakan tugasnya kasi mempunyai fungsi diantaranya, Kasi pemerintahan yang dimana membantu berjalannya pemerintahan disuatu desa tertentu berfungsi sebagai pelaksanaan upaya perlindungan masyarakat, menyusun rancangan regulasi desa, pembinaan masalah pertanahan, melaksanakan manajemen tata praja pemerintahan, pembinaan ketentraman dan ketertiban, penataan dan pengelolaan wilayah, pendataan dan pengelolaan profil desa serta kependudukan. Kasi kesejahteraan yang dimana mengemban tugas dalam mengawasi kesejahteraan masyarakatnya yang mempunyai fungsi diantaranya, melaksanakan pembangunan sarana prasarana perdesaan, pembangunan bidang pendidikan, kesehatan dan tugas sosialisasi serta motivasi masyarakat dibidang budaya, ekonomi, politik, lingkungan hidup, pemberdayaan keluarga, pemuda, olahraga, dan karang taruna. Kasi pelayanan yang dimana membantu melayani masyarakatnya yang mempunyai fungsi diantaranya, melaksanakan penyuluhan dan motivasi terhadap pelaksanaan hak dan kewajiban masyarakat, meningkatkan upaya partisipasi masyarakat, pelestarian nilai social budaya masyarakat, keagamaan, dan ketenagakerjaan[2]. Dalam penentuan kasi terbaik penting untuk menentukan beberapa kriteria yang dijadikan patokan antara lain Lama Bekerja, Pengabdian Masyarakat, Loyalitas Kerja, Usia dan Pendidikan Terakhir. Banyaknya kepala seksi yang kinerjanya kurang baik maka dibutuhkan sistem untuk menentukan kasi terbaik dengan bantuan sistem pendukung keputusan.

Sehingga dibutuhkan suatu Sistem Pendukung Keputusan (SPK) untuk menyelesaikan masalah tersebut, SPK dapat diartikan sebagai suatu sistem informasi yang digunakan untuk mendukung sebuah pengambilan keputusan pada perusahaan atau organisasi. Dipenelitian ini menggunakan metode Operational Competitiveness Rating Analysis (OCRA) merupakan suatu metode yang dapat menghasilkan data-data dalam penentuan kriteria kelayakan Kasi[3]. Beberapa metode yang digunakan pada sistem pendukung keputusan dalam menghasilkan alternatif terbaik diantaranya WP, SAW, TOPSIS, ARAS, MOORA dan OCRA[4], [5].

Adapun penelitian terkait yang membahas tentang metode Operational Competitiveness Rating Analysis (OCRA) yang dapat melakukan proses pengambilan keputusan yang akurat, diantaranya seperti penelitian yang dilakukan oleh Surya Sintamie Hasibuan pada tahun 2021 yang membahas mengenai Penerapan Metode OCRA Dalam Keputusan Rekomendasi Mutasi Jabatan Karyawan, yang pada penelitian ini terdapat 6 kriteria Pengetahuan 
Pekerjaan, Produktivitas Pekerjaan, Kerjasama Tim, Komunikasi, Tanggung Jawab serta Teguran Dan Peringatan. Maka dapat diperoleh hasil perangkingan yaitu alternatif ke-8 dengan nilai 0,45 sebagai alternatif terbaik[6]. Penelitian yang dilakukan oleh Milos Madic, dkk pada tahun 2015 yang membahas mengenai Pemilihan Proses Pemesinan NonKonvensional Menggunakan Metode OCRA, penelitian ini memiliki beberapa kriteria sehingga memperoleh nilai tertinggi 270007.3700[7]. Penelitian yang dilakukan oleh Naomi Titania L.Toruan pada tahun 2021 yang membahas mengenai Pemilihan Pembawa Acara Berita Terbaik Menerapkan Metode OCRA, yang pada penelitian ini terdapat 6 kriteria diantaranya Penampilan, Intonasi, Penguasaan Bahasa, Fokus Kamera, Pengetahuan Umum dan Pengaturan Waktu. Maka dapat diperoleh hasil perangkingan yaitu alternatif Rahmat Juhendra (A6) dengan nilai 1,665 sebagai alternatif terbaik[8]. Penelitian yang dilakukan oleh Askin Ozdagoglu dan Elif Cirkin pada tahun 2019 yang membahas mengenai Pemilihan Perangkat Elektronik dalam Produk Industri Mesin: Analisis Komparatif dengan OCRA dan MAUT, yang dimana penelitian ini terdapat beberapa kriteria sehingga menghasilkan nilai tertinggi 0,512071[9]. Penelitian yang dilakukan oleh Mesran,dkk pada tahun 2019 yang membahas mengenai Metode ROC dan OCRA dalam Penilaian Kinerja Dosen Komputer di STMIK Budi Darma, yang pada penelitian ini terdapat 12 kriteria diantaranya H-Index Scopus, H-Index GS, Dok Scopus, Jurnal Terkareditasi, DokPengabdian, Sertifikat Kompetensi, Pembicara External, Keanggotaan Profesi Dosen, Jabatan Fungsional, Lama Mengajar, Umur, Surat peringatan. Maka dapat diperoleh hasil perangkingan yaitu alternatif ke-2 dengan nilai 4.243 sebagai alternatif terbaik[10]. Dari seluruh penelitian dterkait penulih menjadikan acuan yang tepat dalam pembuatan penelitian ini.

Dari pembahasan di atas maka penulis tertarik untuk melakukan penelitian tentang penentuan Kasi Terbaik dengan menerapkan metode Operational Competitiveness Rating Analysis (OCRA) yang digunakan untuk menghasilkan data-data dalam menentukan kriteria Kasi Terbaik[4]. Penerapan metode OCRA ini dapat memberikan manfaat sehingga dapat memperoleh nilai alternatif terbaik dari sejumlah alternatif dan kriteria tertentu lalu dapat melakukan proses perangkingan. Penilaian yang didasari oleh kriteria-kriteria yang telah dijelaskan diatas maka diharapkan dapat menemukan hasil yang akurat dan tepat.

\section{METODOLOGI PENELITIAN}

\subsection{Sistem Pendukung Keputusan (SPK)}

Sistem Pendukung Keputusan (SPK) adalah suatu sistem informasi yang pada dasarnya memanfaatkan computer dalam ilmu pengetahuan dan manajemen pengetahun dapat digunakan untuk mendukung pengambilan keputusan pada suatu instansi atau organisasi. Dalam arti lain dikatakan sebagai sebuah sistem komputer yang mengolah data menjadi informasi yang digunakan untuk mengambil suatu keputusan pada masalah-masalah yang spesifik dan terstruktur[11] [14].

\subsection{Kasi}

Kasi merupakan suatu unsur pelaksana pada pemerintahan desa yang dimana dipimpin oleh seorang kepala seksi terdiri dari kepala seksi pemerintahan, kepala seksi pelayanan serta kepala seksi kesejahteraan, yang berada di dibawah dan bertanggung jawab kepada kepala desa[1].

\subsection{Metode OCRA}

Metode OCRA (Operational Competitiveness Rating Analysis) suatu pendekatan pengukuran dari ustu kinerja yang relatif oleh model nonparametric yang menjadi dasarnya. OCRA diperkenalkan pertama kali oleh Parkan pada tahun 1994 dan termasuk metode yang sederhana dan sangat berguna dalam menganalisis sektor yang dapat membangkitkan suatu keputusan yang berbeda. Serta memiliki kemampuan dalam membandingkan dan memantau kinerja suatu keputusan dari waktu ke waktu merupakan fitur penting dari metode ini. OCRA dapat diartikan sebagai suatu teknik pengukuran yang efisiensi non-parametrik yang pertama kali diusulkan untuk menangani kinerja masalah pengukuran serta analisis produktivitas, akhir-akhir ini metode OCRA juga dapat menyelesaikan masalah literatur yang menggunakan metode ini untuk bidang lainnya[6], [15], [16]. Berikut merupakan langkah-langkah dalam menyelesaikan masalah dengan menerapkan metode OCRA (Operational Competitiveness Rating Analysis), antara lain sebagai berikut:

1. Pada langkah pertama, membuat matriks keputusan $X_{i j}$ yang menunjukkan alternatif i dibawah kriteria $j[4]$.

$$
\mathrm{X}=\left[\mathrm{X}_{\mathrm{ij}}\right]_{\mathrm{mxn}}=\left[\begin{array}{cccc}
X_{11} & X_{12} & \ldots & X_{1 n} \\
X_{21} & X_{22} & \ldots & X_{2 n} \\
\ldots & \ldots & \ldots & \ldots \\
X_{m 1} & X_{m 2} & \ldots & X_{m n}
\end{array}\right] \mathrm{i}=1, \ldots \mathrm{m} \mathrm{j}=1,2, \ldots, \mathrm{n}
$$

2. Pada langkah kedua, peringkat preferensi yang berhubungan dengan kriteria biaya ditentukan. Nilai dari alternatif pada ktiteria dapat diperkecil dihitung melalui kriteria yang bermanfaat yang tidak di pertimbangkan. Total alternatif yang berhubungan dengan ktiteria yang tidak menguntungkan dapat dihitung dengan rumus berikut : 
Building of Informatics, Technology and Science (BITS)

Volume 3, No 3, Desember 2021 Page: 393-399

ISSN 2684-8910 (media cetak)

ISSN 2685-3310 (media online)

DOI 10.47065/bits.v3i3.1100

$$
\bar{I}_{i}=\sum_{j=1}^{g} w j \frac{\max \left(x_{i j}\right)}{\min \left(x_{i j}\right)}(\mathrm{i}=1,2, \ldots, \mathrm{m} \mathrm{j}=1,2, \ldots \mathrm{g})
$$

3. Pada langkah ketiga, peringkat preferensi linier di setiap alternatif pada kriteria yang tidak menguntungkan dihitung dengan rumus berikut :

$\bar{I}_{i}=\bar{I}_{i} \min \left(\bar{I}_{i}\right)$

4. Pada langkah keempat, peringkat preferensi ini berhubungan dengan kriteria yang ditentukan. Untuk ktiteria yang menguntungkan, alternatif yang memiliki nilai lebih tinggi lebih baik. Peringkat dari total alternative I untuk semua kriteria bermanfaat dihitung dengan rumus berikut :

$\overline{\bar{O}}_{i}=\sum_{j=g+1}^{n} w j \frac{x_{i j}-\max \left(x_{i j}\right)}{\min \left(x_{i j}\right)}(\mathrm{i}=1,2, \ldots, \mathrm{m} \mathrm{j}=\mathrm{g}+1, \mathrm{~g}+2, \ldots \mathrm{n})$

5. Pada langkah kelima, peringkat preferensi linier dihitung untuk kriteria yang bermanfaat dihitung dengan rumus berikut :

$\overline{\bar{O}}_{i}=\bar{O}_{i}-\min \left(\bar{O}_{i}\right)$

6. Pada langkah keenam, nilai dari total preferensi untuk setiap alternatif dihitung dengan menggunakan rumus berikut :

$P_{1}=\left(\overline{\bar{I}}_{i}+\overline{\bar{O}}_{i}\right)-\min (\overline{\bar{I}}+\overline{\bar{O}}) \mathrm{i}=1,2, \ldots \mathrm{m}$

\subsection{Tahapan Penelitian}

Pada penelitian ini terdapat beberapa tahapan penelitian, tahapan-tahapan penelitian tersebut sebagai berikut :

1. Analisis Masalah, penulis menganalisis suatu permasalahan yang dijadikan pokok pembahasan, sebab permasalahan, dan metode yang digunakan.

2. Pengumpulan data, penulis melakukan suatu observasi yang berguna untuk memahami bagaimana prosedur dalam pemilihan Kasi.

3. Studi Literatur, untuk mempelajari dan menambah pemahaman peneliti tentang Sistem Pendukung Keputusan (SPK) secara umum dan metode OCRA (Operational Competitiveness Rating Analysis) serta membaca jurnal dan referensi yang terkait dengan penelitian.

4. Analisis dan Penerapan Metode, tahap penelitian ini diawali dengan, dimulai dengan menganalisis permasalahan yang terjadi dalam pemilihan Kasi. Lalu menganalisa menggunakan metode OCRA (Operational Competitiveness Rating Analysis).

5. Laporan penelitian, pada tahap ini penulis membuat laporan dari keseluruhan penelitian ini, untuk melihat hasil dari penelitian ini telah selesai dengan yang diharapkan, dilanjutkan dengan membuat suatu kesimpulan dari penelitian ini.

Dari tahapan-tahapan diatas dapat digambarkan pada bagan berikut ini :

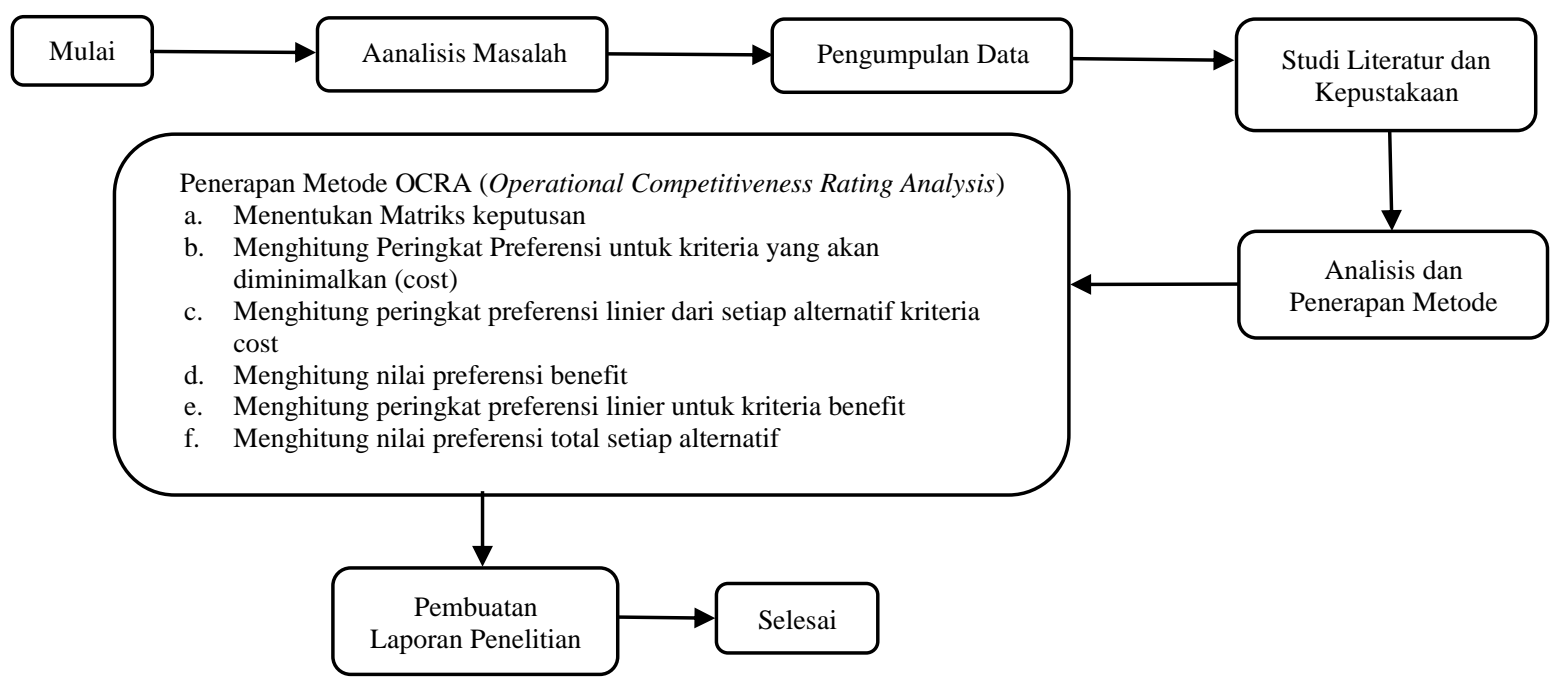

Gambar 1. Kerangka Penelitian

\section{HASIL DAN PEMBAHASAN}




\subsection{Penetapan Alternatif}

Penentuan Kasi bertujuan untuk memberikan pelayanan terbaik bagi masyarakat yang layak menurut kriteria-kriteria yang sudah ditetapkan. Untuk mrnghasilkan pemilihan yang lebih objectif dan tepat sasaran, penulis membuat penenlitian ini menggunakan bantuan metode ROC (Rank Order Centroid) untuk menghasilkan bobot yang dibutuhkan dalam Metode OCRA sebagai perangkingan alternatif. Adapun data alternatif penentuan Kasi pada penelitian ini berjumlah 7 (tujuh) kepala seksi seperti table berikut :

Tabel 1. Data Alternatif Kasi

\begin{tabular}{cl}
\hline Alternatif & \multicolumn{1}{c}{ Nama Kasi } \\
\hline $\mathrm{A}_{1}$ & Dwi Avriani \\
$\mathrm{A}_{2}$ & Adesa Pagira \\
$\mathrm{A}_{3}$ & Dinda Amalia \\
$\mathrm{A}_{4}$ & Ibnu Majid \\
$\mathrm{A}_{5}$ & Wira Sanjaya \\
$\mathrm{A}_{6}$ & Ranti Febrissa \\
$\mathrm{A}_{7}$ & Nurkhaliza Ajura \\
\hline
\end{tabular}

\subsection{Penetapan Kriteria}

Dalam penentuan Kasi terdapat beberapa kriteria seperti pada table 2 dibawah ini :

Tabel 2. Data Kriteria

\begin{tabular}{cccc}
\hline Kriteria & Keterangan & Bobot & Jenis \\
\hline $\mathrm{C}_{1}$ & Lama Bekerja & 0,46 & Benefit \\
$\mathrm{C}_{2}$ & Pengabdian Masyarakat & 0,26 & Benefit \\
$\mathrm{C}_{3}$ & Loyalitas Kerja & 0,16 & Benefit \\
$\mathrm{C}_{4}$ & Usia & 0,09 & Cost \\
$\mathrm{C}_{5}$ & Pendidikan Terakhir & 0,04 & Cost \\
\hline
\end{tabular}

Keterangan kriteria :

Lama Bekerja

Pengabdian masyarakat

Royalitas Kerja

Usia

Pendidikan terakhir
: Lamanya Seorang Kasi Bekerja (tahun)

: Sikap Kasi selama mangabdi di Desa

: Sikap kepatuhan Kasi dalam bekerja

: Maksimal 40 tahun

: Jenjang pendidikan terakhir

Penentuan Kasi yang memenuhi kriteria sebagai persyaratan menjadi yang terbaik. Pada pembobotan kepentingan setiap kriteria menggunakan metode ROC (Rank Order Centroid) merupakan salah satu metode yang digunakan untuk mengasilkan nilai bobot yang akan digunakan dalam perangkingan pada sistem pendukung keputusan[17].

Tabel 3. Data Kriteria

\begin{tabular}{cccccc}
\hline Alternatif & $\begin{array}{c}\text { Lama } \\
\text { Bekerja } \\
\left(\mathrm{C}_{1}\right)\end{array}$ & $\begin{array}{c}\text { Pengabdian Masyarakat } \\
\left(\mathrm{C}_{2}\right)\end{array}$ & $\begin{array}{c}\text { Loyalitas Kerja } \\
\left(\mathrm{C}_{3}\right)\end{array}$ & $\begin{array}{c}\text { Usia } \\
\left(\mathrm{C}_{4}\right)\end{array}$ & $\begin{array}{c}\text { Pendidikan } \\
\text { Terakhir }\left(\mathrm{C}_{5}\right)\end{array}$ \\
\hline $\mathrm{A}_{1}$ & 6 & Cukup & Cukup & 30 & SMA \\
$\mathrm{A}_{2}$ & 3 & Baik & Kurang & 26 & D3 \\
$\mathrm{A}_{3}$ & 7 & Kurang & Baik & 33 & SMA \\
$\mathrm{A}_{4}$ & 8 & Cukup & Sangat Baik & 42 & SMA \\
$\mathrm{A}_{5}$ & 3 & Sangat Baik & Baik & 37 & S1 \\
$\mathrm{A}_{6}$ & 5 & Kurang & Cukup & 24 & SMA \\
$\mathrm{A}_{7}$ & 2 & Cukup & Kurang & 40 & SMA \\
\hline
\end{tabular}

Tabel 3 berikut dapat dijelaskan bahwa yang berjenis linguistik diantaranya, Sangat Baik, Baik, Cukup dan Kurang Baik, maka diperlukan pembobotan agar mendapatkan nilai angka seperti table 4 berikut :

Tabel 4. Bobot Nilai Kriteria $\mathrm{C}_{2}$ dan $\mathrm{C}_{3}$

\begin{tabular}{cc}
\hline Keterangan & Nilai \\
\hline Sangat Baik & 4 \\
Baik & 3 \\
Cukup & 2 \\
Kurang & 1 \\
\hline
\end{tabular}


Building of Informatics, Technology and Science (BITS)

Volume 3, No 3, Desember 2021 Page: 393-399

ISSN 2684-8910 (media cetak)

ISSN 2685-3310 (media online)

DOI 10.47065/bits.v3i3.1100

Tabel 5. Bobot Nilai Kriteria $C_{5}$

\begin{tabular}{cc}
\hline Keterangan & Nilai \\
\hline S1 & 3 \\
D3 & 2 \\
SMA & 1 \\
\hline
\end{tabular}

Pada kriteria $\mathrm{C}_{2}, \mathrm{C}_{3}$ dan $\mathrm{C}_{5}$ telah dilakukan proses pembobotan seperti table 5 berikut :

Tabel 6. Rating Kecocokan Setelah Pembobotan

\begin{tabular}{cccccc}
\hline Alternatif & $\mathrm{C}_{1}$ & $\mathrm{C}_{2}$ & $\mathrm{C}_{3}$ & $\mathrm{C}_{4}$ & $\mathrm{C}_{5}$ \\
\hline $\mathrm{A}_{1}$ & 6 & 2 & 2 & 30 & 1 \\
$\mathrm{~A}_{2}$ & 3 & 3 & 1 & 26 & 2 \\
$\mathrm{~A}_{3}$ & 7 & 1 & 3 & 33 & 1 \\
$\mathrm{~A}_{4}$ & 8 & 2 & 4 & 42 & 1 \\
$\mathrm{~A}_{5}$ & 3 & 4 & 3 & 37 & 3 \\
$\mathrm{~A}_{6}$ & 5 & 1 & 2 & 24 & 1 \\
$\mathrm{~A}_{7}$ & 2 & 2 & 1 & 40 & 1 \\
\hline
\end{tabular}

\subsection{Penetapan Metode OCRA (Operational Competitiveness Rating Analysis)}

Berikut ini merupakan tahapan yang dibutuhkan dalam mementukan Kasi terbaik menggunakan metode OCRA (Operational Competitiveness Rating Analysis) :

1. Membentuk matriks keputusan

$$
X=\left[x_{i j}\right]_{m x n}=\left[\begin{array}{lllll}
6 & 2 & 2 & 30 & 1 \\
3 & 3 & 1 & 26 & 2 \\
7 & 1 & 3 & 33 & 1 \\
8 & 2 & 4 & 42 & 1 \\
3 & 4 & 3 & 37 & 3 \\
5 & 1 & 2 & 24 & 1 \\
2 & 2 & 1 & 40 & 1
\end{array}\right]
$$

2. Menghitung peringkat preferensi untuk kriteria yang akan diminimalkan (cost) untuk kriteria C4 dan C5

$$
\begin{aligned}
& \bar{I}_{1}=\sum\left(0.09 \frac{40-30}{24}\right)+\left(0.04 \frac{3-1}{1}\right)=\sum 0.037+0.08=0.117 \\
& \bar{I}_{2}=\sum\left(0.09 \frac{40-26}{24}\right)+\left(0.04 \frac{3-2}{1}\right)=\sum 0.052+0.04=0.092 \\
& \bar{I}_{3}=\sum\left(0.09 \frac{40-33}{24}\right)+\left(0.04 \frac{3-1}{1}\right)=\sum 0.026+0.08=0.106 \\
& \bar{I}_{4}=\sum\left(0.09 \frac{40-42}{24}\right)+\left(0.04 \frac{3-1}{1}\right)=\sum 0.007+0.08=0.087 \\
& \bar{I}_{5}=\sum\left(0.09 \frac{40-37}{24}\right)+\left(0.04 \frac{3-3}{1}\right)=\sum 0.011+0.000=0.011 \\
& \bar{I}_{6}=\sum\left(0.09 \frac{40-24}{24}\right)+\left(0.04 \frac{3-1}{1}\right)=\sum 0.059+0.08=0.139 \\
& \bar{I}_{7}=\sum\left(0.09 \frac{40-40}{24}\right)+\left(0.04 \frac{3-1}{1}\right)=\sum 0.000+0.08=0.08
\end{aligned}
$$

3. Menghitung peringkat preferensi linear dari setiap alternatif yang tidak menguntungkan (Cost)

$\overline{\bar{I}}_{1}=0.117-0.011=0.106$

$\overline{\bar{I}}_{2}=0.092-0.011=0.081$

$\overline{\bar{I}}_{3}=0.106-0.011=0.095$

$\overline{\bar{I}}_{4}=0.087-0.011=0.076$

$\overline{\bar{I}}_{5}=0.011-0.011=0.000$

$\overline{\bar{I}}_{6}=0.139-0.011=0.128$

$\overline{\bar{I}}_{7}=0.08-0.011=0.069$

4. Menghitung peringkat preferensi untuk kriteria yang dimaksimalkan (Benefit) untuk kriteria C1, C2, dan C3.

$$
\bar{O}_{1}=\sum\left(0.456 \frac{6-2}{2}\right)+\left(0.256 \frac{2-1}{1}\right)+\left(0.156 \frac{2-1}{1}\right)=\sum 0.912+0.256+0.156=1.324
$$




$$
\begin{aligned}
& \bar{O}_{2}=\sum\left(0.456 \frac{3-2}{2}\right)+\left(0.256 \frac{3-1}{1}\right)+\left(0.156 \frac{1-1}{1}\right)=\sum 0.228+0.512+0.000=0.74 \\
& \bar{O}_{3}=\sum\left(0.456 \frac{7-2}{2}\right)+\left(0.256 \frac{1-1}{1}\right)+\left(0.156 \frac{3-1}{1}\right)=\sum 1.14+0.000+0.312=1.452 \\
& \bar{O}_{4}=\sum\left(0.456 \frac{8-2}{2}\right)+\left(0.256 \frac{2-1}{1}\right)+\left(0.156 \frac{4-1}{1}\right)=\sum 1.368+0.256+0.468=2.092 \\
& \bar{O}_{5}=\sum\left(0.456 \frac{3-2}{2}\right)+\left(0.256 \frac{4-1}{1}\right)+\left(0.156 \frac{3-1}{1}\right)=\sum 0.228+0.768+0.312=1.308 \\
& \bar{O}_{6}=\sum\left(0.456 \frac{5-2}{2}\right)+\left(0.256 \frac{1-1}{1}\right)+\left(0.156 \frac{2-1}{1}\right)=\sum 0.684+0.000+0.156=0.84 \\
& \bar{O}_{7}=\sum\left(0.456 \frac{2-2}{2}\right)+\left(0.256 \frac{2-1}{1}\right)+\left(0.156 \frac{1-1}{1}\right)=\sum 0.000+0.256+0.000=0.256
\end{aligned}
$$

5. Menghitung perangkat preferensi linear diitung untuk kriteria menguntungkan (Benefit)

$$
\begin{aligned}
& \overline{\bar{O}}_{1}=1.324-0.256=1.068 \\
& \overline{\bar{O}}_{2}=0.74-0.256=0.484 \\
& \overline{\bar{O}}_{3}=1.452-0.256=1.196 \\
& \overline{\bar{O}}_{4}=2.092-0.256=1.836 \\
& \overline{\bar{O}}_{5}=1.308-0.256=1.052 \\
& \overline{\bar{O}}_{6}=0.84-0.256=0.584 \\
& \overline{\bar{O}}_{7}=0.256-0.256=0.000
\end{aligned}
$$

6. Menghitung nilai preferensi total untuk setiap alternatif

$$
\begin{aligned}
& P_{1}=(0.106+1.068)-0.565=0.609 \\
& P_{2}=(0.081+0.484)-0.565=0.000 \\
& P_{3}=(0.095+1.196)-0.565=0.726 \\
& P_{4}=(0.076+1.836)-0.565=1.347 \\
& P_{5}=(0.000+1.052)-0.565=0.487 \\
& P_{6}=(0.128+0.584)-0.565=0.147 \\
& P_{7}=(0.69+0.000)-0.565=0.125
\end{aligned}
$$

Berdasarkan perhitungan diatas dengan menggunakan metode OCRA (Operational Competitiveness Rating Analysis) maka diperoleh hasil perangkingan yang dapat dilihat pada table 6 berikut :

Tabel 7. Nilai Preferensi

\begin{tabular}{cccc}
\hline Alternatif & Nama Kasi & Nilai Preferensi & Peringkat \\
\hline $\mathrm{A}_{1}$ & Dwi Avriani & 0.609 & 3 \\
$\mathrm{~A}_{2}$ & Adesa Pagira & 0.000 & 7 \\
$\mathrm{~A}_{3}$ & Dinda Amalia & 0.726 & 2 \\
$\mathrm{~A}_{4}$ & Ibnu Majid & 1.347 & 1 \\
$\mathrm{~A}_{5}$ & Wira Sanjaya & 0.487 & 4 \\
$\mathrm{~A}_{6}$ & Ranti Febrissa & 0.147 & 5 \\
$\mathrm{~A}_{7}$ & Nurkhaliza Ajura & 0.125 & 6 \\
\hline
\end{tabular}

Dari tabel 7 terlihat hasil pengujian ketujuh Kasi dapat disimpulkan bahwa alternative yang dipilih sebagai Kasi terbaik adalah alternative ke-empat (A4) yang dianggap layak menjadi Kasi terbaik yaitu Ibnu Majid dengan nilai preferensi 1.347 .

\section{KESIMPULAN}

Berdasarkan penelitian yang telah dilakukan maka dapat disimpulkan bahwa metode OCRA (Operational Competitiveness Rating Analysis) dapat digunakan untuk penentuan Kasi terbaik. Sistem pendukung keputusan dapat digunakan sebagai alat bantu untuk menentukan Kasi terbaik dengan perolehan nilai alternatif terbaik yang berada pada $\mathrm{A}_{4}$ dengan nama Ibnu Majid sebesar 1.347 untuk membantu kinerja pemerintahan desa dalam menentukan Kasi yang produktif semasa bekerja menggunakan metode OCRA (Operational Competitiveness Rating Analysis) sehingga dapat menghasilkan nilai pereferensi terbaik dan alternatif terbaik sebagai peringkat pertama.

\section{REFERENCES}

[1] P. P. Desa, “Agus Dwiyanto, Reformasi Tata Pemerintahan dan Otonomi Daerah, Pusat Studi Kependudukan dan Kebijakan Universitas Gadjah Mada , Bagir Manan , Menyongsong Fajar Otonomi Daerdi , Pusat Studi Fakultas Hukum Universitas 
Islam Indonesia ," vol. 2, no. 1, pp. 40-50, 2004.

[2] S. Sihombing and J. Sagala, "Sistem Pendukung Keputusan Pemilhan Calon Perangkat Desa Tapian Nauli Kecamatan Lintong Nihuta Dengan Metode Simple Additive Weighting (SAW)," METHOMIKA J. Manaj. Inform. dan Komputerisasi Akunt., vol. 4, no. 1, pp. 120-125, 2020.

[3] I. Herman Firdaus, G. Abdillah, F. Renaldi, and U. Jenderal Achmad Yani Jl, "Sistem Pendukung Keputusan Penentuan Karyawan Terbaik Menggunakan Metode Ahp Dan Topsis," Semin. Nas. Teknol. Inf. dan Komun., vol. 2016, no. Sentika, pp. 2089-9815, 2016.

[4] N. Kundakc1, “An Integrated Multi-Criteria Decision Making Approach for Tablet Computer Selection,” Eur. J. Multidiscip. Stud., vol. 5, no. 1, p. 36, 2017.

[5] I. J. T. Situmeang, S. Hummairoh, S. M. Harahap, and Mesran, "Application of SAW ( Simple Additive Weighting ) for the Selection of Campus Ambassadors," IJICS (International J. Informatics Comput. Sci., vol. 5, no. 1, pp. 21-28, 2021.

[6] S. S. Hasibuan, "Penerapan Metode Operational Competitiveness Rating Analysis ( OCRA ) Dalam Keputusan Rekomendasi Mutasi Jabatan Karyawan," vol. 1, no. 1, pp. 1-8, 2021.

[7] M. Madić, D. Petković, and M. Radovanović, "SELECTION OF NON-CONVENTIONAL MACHINING PROCESSES USING THE OCRA METHOD,” vol. 10, no. 1, pp. 61-73, 2015.

[8] N. T. L. Toruan, "Sistem Pendukung Keputusan Pemilihan Pembawa Acara Berita Terbaik Menerapkan Metode OCRA," Bull. Comput. Sci. Res., vol. 1, no. 3, pp. 71-78, 2021.

[9] A. Sciences, "ELECTRONIC DEVICE SELECTION IN INDUSTRIAL PRODUCTS AND MACHINERY INDUSTRY : COMPARATIVE ANALYSIS WITH OCRA AND MAUT,” pp. 119-134, 2019.

[10] T. Limbong et al., Sistem Pendukung Keputusan: Metode \& Implementasi. Medan: Yayasan Kita Menulis, 2020.

[11] R. Watrianthos, E. F. S. Simanjorang, M. Syaifullah, and I. R. Munthe, "Penerapan Metode Promethee Sebagai Sistem Pendukung Keputusan Pemeringkatan Siswa,” vol. 3, no. 4, pp. 381-386, 2019.

[12] D. Nofriansyah, Konsep Data Mining Vs Sistem Pendukung Keputusan. 2015.

[13] D. Nofriansyah, Multi Criteria Decision Making. Yogyakarta: Deepublish, 2017.

[14] J. E. and L. T. P. Turban, A. Efraim, Decision Support System and Intelegence Systems, 7th ed. Jogjakarta: Penerbit Andi, 2015.

[15] A. Karim, S. Esabella, Kusmanto, Mesran, and U. Hasanah, "Analisa Penerapan Metode Operational Competitiveness Rating Analysis ( OCRA ) dan Metode Multi Attribute Utility Theory ( MAUT ) Dalam Pemilihan Calon Karyawan Tetap Menerapkan Pembobotan Rank Order Centroid ( ROC ),” J. Media Inform. Budidarma, vol. 5, no. 4, pp. 1674-1687, 2021.

[16] M. Mesran, T. M. Diansyah, and F. Fadlina, "Implemententasi Metode Rank Order Cendroid (ROC) dan Operational Competitiveness Rating Analysis (OCRA) dalam Penilaian Kinerja Dosen Komputer Menerapkan (Studi Kasus: STMIK Budi Darma),” Pros. Semin. Nas. Ris. Inf. Sci., vol. 1, no. 0, p. 822, Sep. 2019.

[17] N. Astiani, D. Andreswari, and Y. Setiawan, "OBAT HERBAL UNTUK BERBAGAI PENYAKIT DENGAN METODE ROC ( RANK ORDER CENTROID ) DAN METODE,” vol. 12, no. 2, pp. 125-140, 2016. 